$\xi=-1$

\title{
Comparing is code specified flexural strength of concrete with split tensile strength by conducting test on cubes
}

\author{
Usha $M^{1}$ *, P. Poluraju ${ }^{2}$ \\ ${ }^{1}$ M. Tech Student, Civil Engineering Department K L University, Guntur - 522502, Andhra Pradesh, India \\ ${ }^{2}$ Associate Professor, Civil Engineering Department, K L University, Guntur-522502, Andhra Pradesh, India \\ *Corresponding author E-mail: ushaharishsrm@gmail.com
}

\begin{abstract}
The present study aims at investigating the Code IS 456 specified flexure strengths of concrete. This investigation involved carrying out a split tensile test on cubes. The design mix calculations for M20, M25, M30, M40, M50 and M60 were done. Steel fibers were used to improve the resistance of fracture and tensile strength of concrete by its volume percentage of $1 \%, 2 \%$ and $3 \%$ for all the grades. The test was carried out on the universal testing machine using billets to apply point load on exactly mid of the cube. It was observed that the code specified flexure strength is a conservative estimate.
\end{abstract}

Keywords: Flexural Strength; Split Tensile Test; Fiber Reinforced Concrete; Cracks; Ductility.

\section{Introduction}

Concrete is a homogeneous composite material which is very good in taking high compressive stresses and very weak in direct tension. The tensile stresses developed in concrete members are the result of flexure, shrinkage and temperature changes. Often cracking in the concrete is a result of tensile strength being exceeded. The maximum direct tensile capacity of the concrete is only about 7 to 15 percent of the compressive strength. Performing direct tensile test on a concrete specimen is difficult, as it requires purely axial tensile force to be applied, and shall be free of any misalignment and any secondary stress in the specimen at the grips of the testing machine. Therefore, tests are performed in the indirect way, usually the flexure test or the cylinder splitting test as per IS 5816 [1]. However, the approximate tensile strength can be estimated from the known compressive strength of concrete using the formula $f_{c r}=0.7 \sqrt{ }$ fck, where $f_{c r}$ is the modulus of rupture as specified in IS 456 [2].

Cylinder splitting test is the most commonly employed and easiest technique for determination of tensile properties of concrete. The main reason for this is simplicity in preparation and performance of the test and the relatively narrow dispersion of test results. The specimen is a standard cylinder as used for compression test is loaded in compression on its side along a diametral plane. The failure occurs by splitting of the cylinder along the loaded plane. The splitting tensile strength $\mathrm{f}_{\mathrm{ct}}$ is evaluated by using $\mathrm{fct}_{\mathrm{ct}}=2 \mathrm{P} / \pi \mathrm{dL}$, where ' $\mathrm{P}$ ' is maximum applied load, ' $\mathrm{d}$ ' is the diameter and ' $\mathrm{L}$ ' is the length of the cylinder. It has been found that for normal density concrete the splitting tensile strength is about two-thirds of the modulus of rupture i.e., $\mathrm{f}_{\mathrm{cr}}$

A lot of research is being carried out to find and enhance the tensile strength of concrete by various methods which include using fibers of various material such as steel, plastic, basalt fibers etc. The fibers affect the flow of concrete, and the mode of failure was changed from brittle to ductile [3]. Increase in ductility up to $4 \%$ can be achieved compared to the conventional concrete of grade
M30 when polypropylene fibers are used [4]. There will be a significant improvement in tensile strength with the inclusion of steel fibers, and maximum gain in flexural strength of concrete depends on the number of fiber contents [5]. The bonding of concrete can be increased by adding fibers, it also helps in resisting the rupture of concrete [6]. The Crack initiation is majorly affected by the concrete strength, specimen geometry and test setup [7]. Since most of the research works on the tensile strength of concrete were carried out on the cylindrical splitting tensile, while the current study is an experimental investigation on splitting tensile test on cubes of various grades and with and without fibers, varying in total volume percentage.

\section{Experimental programme}

The design mix calculations were made as per IS 10262 [8] to arrive at the proportions for concrete of various grades and are shown in Table 1. The Pozzolana Portland Cement of fly ash based was used since the rate of the heat of hydration is generally low for fly ash based. The crushed granite rock with maximum $20 \mathrm{~mm}$ size was used as coarse aggregate and the Zone-II type fine aggregate was used. The specific gravity of cement, fine and coarse aggregate are $3.15,2.6$ and 2.75 respectively.

Table 1: Details of Design Mix Proportions

\begin{tabular}{llll} 
& \multicolumn{3}{l}{ Table 1: Details of Design Mix Proportions } \\
\hline Grade & $\begin{array}{l}\text { Proportion }(\mathrm{C}: \\
\text { FA:CA) }\end{array}$ & W/C Ratio & $\begin{array}{l}\text { Target Strength } \\
\left(\mathrm{N} / \mathrm{mm}^{2}\right)\end{array}$ \\
\hline M20 & $1: 2.51: 3.98$ & 0.5 & 26.6 \\
M25 & $1: 2.31: 3.72$ & 0.5 & 31.6 \\
M30 & $1: 2.21: 3.65$ & 0.45 & 38.25 \\
M40 & $1: 1.93: 3.33$ & 0.45 & 48.25 \\
M50 & $1: 1.83: 3.16$ & 0.45 & 58.25 \\
M60 & $1: 1.71: 2.94$ & 0.45 & 68.25 \\
\hline
\end{tabular}

The cold drawn type mild steel hooked end fibers of tensile strength of $1150 \mathrm{~N} / \mathrm{mm} 2$ whose diameter and length are $0.75 \mathrm{~mm}$ and $65 \mathrm{~mm}$ respectively, were used to investigate the change in the 
tensile strength of the concrete if varied by $1 \%, 2 \%$ and $3 \%$ of the volume of the concrete as shown in Fig. 1. Therefore, record the effect of fibers when mixed in concrete.
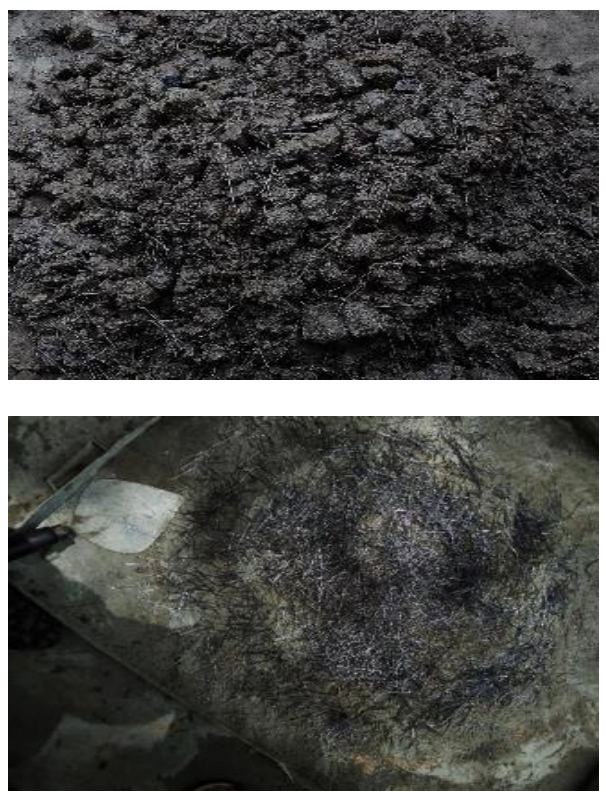

Fig. 1: Fibres before and after Mix.

\subsection{Test setup}

The testing was carried out on a universal testing machine of 100 Ton capacity. The billets of $16 \mathrm{~mm}$ size were placed on the loading platens, above and below the cube on the universal testing machine. The loads were applied at the constant rate onto the billets to ensure the load is concentrated at the mid of the cube. Fig. 2 (a) \& (b) show the loading condition and (c) shows the actual loading arrangement.

The splitting tensile strength of cube was estimated using $\mathrm{f}_{\mathrm{ct}}=2 \mathrm{P} /$ $4 \mathrm{~s}^{2}$ where ' $\mathrm{s}$ ' is side dimension of the cube in $\mathrm{mm}$. The deviation in the formula was made to bring about the stress in the cube since, in $\mathrm{f}_{\mathrm{ct}}=2 \mathrm{P} / \pi \mathrm{dL}$ where $\pi \mathrm{dL}$ is the stress on the diametral plane.
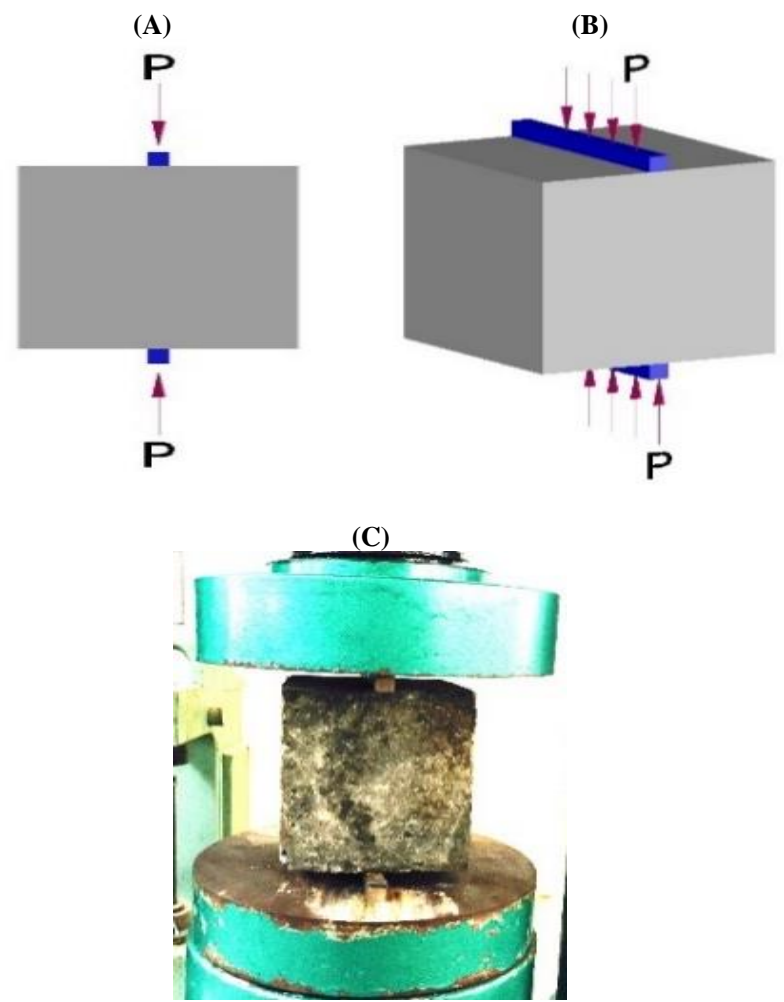

Fig. 2: Loading Condition: (A) Load Condition in Front View (B) Iso View of Loading (C) Actual Setup of Load

\section{Result and discussions}

\subsection{Crack pattern and failure mode}

The failure of the cube was more like that of failure of the cylinder in splitting tensile test. The cracks were observed to have appeared at the mid of the cube exactly under the load point.
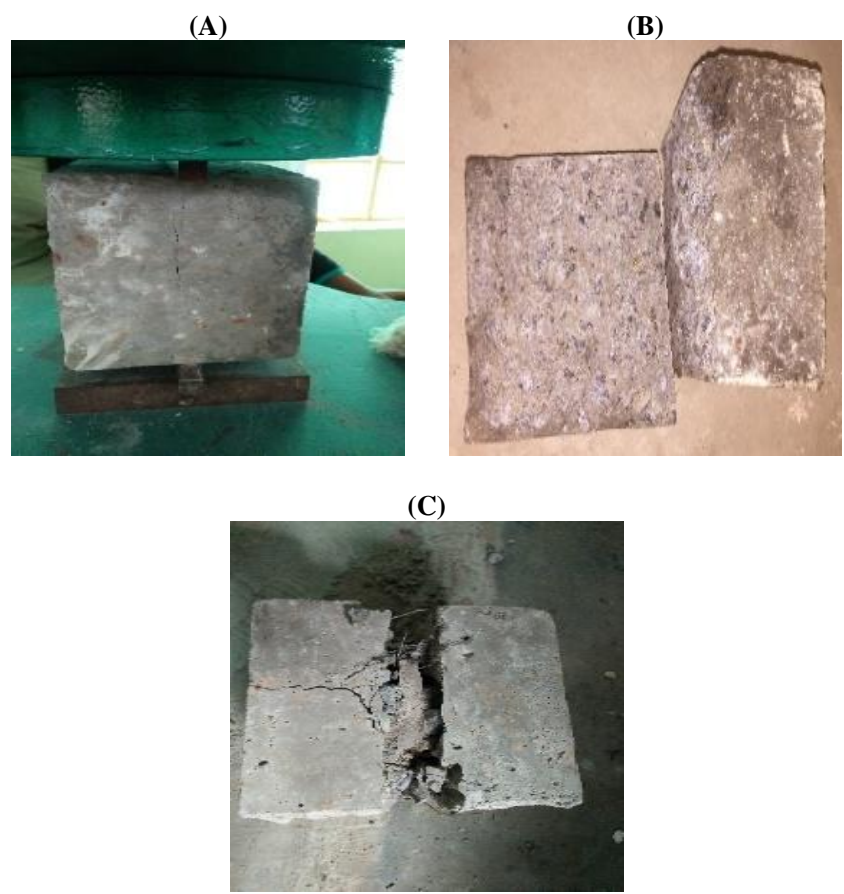

Fig. 3: (A) Crack Propagation (B) Brittle Failure (C) Ductile Failure and Crack Perpendicular to Load Axis.

The initial crack propagation in most of the samples appeared at the $1 / 3^{\text {rd }}$ distance of the depth of the cube as shown in Fig. 3 (a). The failure of the cubes without fibers were found to fail in brittle mode (b) and that of with fibers were found to fail in ductile mode (c). The fibers were found elongated in the direction of the load axis. It was also observed that once the crack has reached the full depth of the cubes with fibers in the direction of the loading axis, the crack was initiated in the direction perpendicular to the axis of the load.

a) Split Tensile Strength

Table 2 shows the results of splitting tensile test

Table 2: Splitting Tensile Strength of Cubes at 28 Days (Average of 3 Samples for Each Percentage of Fibres)

\begin{tabular}{lll}
\hline \multirow{3}{*}{ M20 } & $0 \%$ Fibers & 2.02 \\
& $1 \%$ Fibers & 2.66 \\
& $2 \%$ Fibers & 2.49 \\
& $3 \%$ Fibers & 2.23 \\
\hline \multirow{3}{*}{ M25 } & $0 \%$ Fibers & 2.45 \\
& $1 \%$ Fibers & 2.97 \\
& $2 \%$ Fibers & 2.83 \\
& $3 \%$ Fibers & 2.3 \\
M30 & $0 \%$ Fibers & 2.28 \\
& $1 \%$ Fibers & 2.35 \\
& $2 \%$ Fibers & 2.5 \\
& $3 \%$ Fibers & 3.43 \\
M40 & $0 \%$ Fibers & 2.86 \\
& $1 \%$ Fibers & 2.52 \\
& $2 \%$ Fibers & 3.68 \\
M50 & $3 \%$ Fibers & 3.28 \\
& $0 \%$ Fibers & 3.08 \\
& $1 \%$ Fibers & 3.18 \\
M60 & $2 \%$ Fibers & 3 \\
& $3 \%$ Fibers & 3.73 \\
& $0 \%$ Fibers & 2.87 \\
& $1 \%$ Fibers & 2.46 \\
& $2 \%$ Fibers & 2.54 \\
& $3 \%$ Fibers & 1.99 \\
\hline
\end{tabular}


As discussed earlier tensile strength of the concrete cube after splitting tensile test was found to be approximately two third of the modulus of rupture. And adding fibers had increased the tensile strength of concrete to the range of three forth to one - one fourth of the modulus of rupture. It was also observed that the variation in the strength of the specimens of two percent of fibers by volume had exhibited the consistent ratio across various grades. However, the approximation of two-third of the modulus of rupture was found to be overestimation for higher grades such as M50 and M60.

Through linear regression, the following equations (a) to (f) were arrived to find the tensile strength of various grades of concrete under varying percentage of steel fibers $\left(\mathrm{V}_{\mathrm{f}}\right)$.

a) M20

$f_{c t}(20)=0.1235 V_{f}^{3}-0.7812 V_{f}^{2}+1.3007 V_{f}+2.0201$

b) $\mathrm{M} 25$

$\mathrm{f}_{\mathrm{ct}}(25)=0.0484 \mathrm{~V}_{\mathrm{f}}^{3}-0.4796 \mathrm{~V}_{\mathrm{f}}^{2}+0.9544 \mathrm{~V}_{\mathrm{f}}+2.4489$

c) M30

$f_{\text {ct }}(30)=0.1145 V_{f}{ }^{3}-0.3016 V_{f}{ }^{2}+0.2562 V_{f}+2.2817$

d) M40

$f_{c t}(40)=-0.5099 V_{f}{ }^{3}+2.2817 V_{f}{ }^{2}-2.117 V_{f}+2.8631$

e) M50

$f_{\text {ct }}(50)=0.2004 V_{f}^{3}-0.7448 V_{f}^{2}+0.6461 V_{f}+3.0811$

f) M60

$f_{c t}(60)=-0.1889 V_{f}{ }^{3}+0.8157 V_{f}^{2}-1.0409 V_{f}+2.874$

\section{Conclusions}

- The flexural strength of concrete i.e., fcr $=0.7 * V_{\text {fck }}$ is a conservative estimate.

- Portland Pozzolana cement has an impact on the compression strength of concrete. Since it takes longer time to gain its full compressive strength.

- Heat is released as the strain in the concrete increases.

- Fiber induced concrete has a compact structure as the watercement ratio is relatively low.

- The failure mode changes from brittle to ductile when fibers are used.

- The fibers in the concrete were found to be elongated in the direction of the load axis.

- Fiber reinforced concrete can be used where reinforcement cannot be used for increasing the tensile strength and achieve the ductility. Ex. Tunnel linings, Furnace linings etc.

- Fiber reinforced concrete can be used for retrofitting and rehabilitation, where strength and ductility should be increased.

\section{References}

[1] IS: 5816-1959, Splitting Tensile strength of concrete - Method of test, Bureau of Indian Standards.

[2] IS: 456-2000, Plain and Reinforced Concrete - Code of Practice, Bureau of Indian Standards.

[3] R. N. Nibudey, P. B. Nagarnaik, D. K. Parbat, and A. M. Pande (2013), Strengths Prediction of Plastic Fiber Reinforced concrete (M30), International Journal of Engineering Research and Applications, Vol. 3, Issue 1, pp.1818-1825.
[4] M. Tamil Selvi and T.S. Thandavamoorthy (2013), FIE, Studies on the Properties of Steel and Polypropylene Fiber Reinforced Concrete without any Admixture, International Journal of Engineering and Innovative Technology (IJEIT), Vol. 3, Issue 1, pp. 411-416.

[5] R. M. Sawant, Y. M. Ghugal, and J.A Khan (2015), Evaluation of Split Tensile Strength of High Strength Fiber Reinforced Concrete, International Journal of Technical Research and Applications eISSN: 2320-8163, Vol. 3, Issue 6, pp. 243-247.

[6] P. Jyotsna Devi, and K. Srinivasa Rao (2014), Study on the Flexural and Split Tensile Strengths of Steel Fibres Reinforced Concrete at High Temperatures, International Journal of Education and Applied Research, Vol. 4, Issue Spl-2, pp. 49-53.

[7] V. Malárics, and H.S. Müller (2010), Evaluation of the splitting tension test for concrete from a fracture mechanical point of view, Korea Concrete Institute, Seoul, Proceedings of FraMCoS-7, pp. 709-716.

[8] IS: 10262-2009, Concrete Mix Proportioning - Guidelines, Bureau of Indian Standards. 